

\section{Biometric assessments of the posterior fossa by fetal MRI: a systematic review}

\section{Running title}

$2 \mathrm{D}$ biometric assessments of the posterior fossa by fetal MRI

\section{Manuscript count}

Word count: 3260

Table count: 3

Figure count: 4

\section{Authors}

Katie Mckinnon ${ }^{1,2}$, Giles S Kendall ${ }^{1,2}$, Cally J Tannn ${ }^{1,3}$, Leigh Dyet ${ }^{1,2}$, Magdalena Sokolska ${ }^{2,4}$, Kelly

Pegoretti Baruteau ${ }^{2,5}$, Neil Marlow ${ }^{1,2}$, Nicola J Robertson ${ }^{1,2}$, Donald Peebles ${ }^{2,6}$, Latha Srinivasan ${ }^{1,2}$

1. University College London Hospitals NHS Foundation Trust, Neonatal Department

2. University College London, Institute for Women's Health

3. London School of Hygiene and Tropical Medicine, MARCH Centre

4. University College London Hospitals NHS Foundation Trust, Medical Physics Department

5. University College London Hospitals NHS Foundation Trust, Radiology Department

6. University College London Hospitals NHS Foundation Trust, Obstetric Department

Neonatal Department, $2^{\text {nd }}$ Floor North, 250 Euston Road, NW1 2PG

Katie.mckinnon@nhs.net

$+442034478094$

This article has been accepted for publication and undergone full peer review but has not been through the copyediting, typesetting, pagination and proofreading process which may lead to differences between this version and the Version of Record. Please cite this article as doi: $10.1002 / \mathrm{pd} .5874$ 


\section{Conflicts of interest}

No conflicts of interest to declare

\section{Funding}

This systematic review was performed as part of a Marcel Levi Fellowship at University College London Hospital.

\section{What is already known about this topic?}

- Posterior fossa abnormalities are one of the most common reasons for fetal MRI.

- Biometric measurements of the posterior fossa are well characterised in antenatal ultrasound studies.

- Many different measurements have been used to assess the posterior fossa on fetal MRI in health and disease, but not consistently.

\section{What does this study add?}

- This review identified 11 validated 2D biometric measurements were used in 10 or more studies for assessment of the posterior fossa on fetal MRI.

- Consistent application of these measurements will be useful in delineation of different types of posterior fossa abnormalities.

\section{Data availability}

Data available on request from the authors 


\section{Abstract}

Posterior fossa abnormalities (PFAs) are commonly identified within routine screening and are a frequent indication for fetal magnetic resonance imaging (MRI). Although biometric measurements of the posterior fossa (PF) are established on fetal ultrasound and MRI, qualitative visual assessments are predominantly used to differentiate PFAs. This systematic review aimed to assess 2-dimensional (2D) biometric measurements currently in use for assessing the PF on fetal MRI to delineate different PFAs. The protocol was registered (PROSPERO ID CRD42019142162). Eligible studies included T2-weighted MRI PF measurements in fetuses with and without PFAs, including measurements of the PF, or other brain areas relevant to PFAs. 59 studies were included -6859 fetuses had 62 2D PF and related measurements. These included linear, area and angular measurements, representing measures of PF size, cerebellum/vermis, brainstem, and supratentorial measurements. 11 measurements were used in 10 or more studies and at least 1200 fetuses. These dimensions were used to characterise normal for gestational age, diagnose a range of pathologies, and predict outcome. A selection of validated 2D biometric measurements of the PF on fetal MRI may be useful for identification of PFA in different clinical settings. Consistent use of wese measures, both clinically and for research, is recommended.

\section{Acknowledgements}

N/A 


\section{Introduction}

The cerebellum starts developing early in brain formation, but has ongoing development into the postnatal period.(1) This makes it vulnerable to developmental events, making posterior fossa abnormalities (PFAs) one of the most common fetal intracranial abnormalities, and one of the most common reasons for referral for fetal magnetic resonance imaging (MRI).(2) There are a range of PFA diagnoses, and differentiating these at an early stage of development is challenging,(3) making accurate antenatal counselling of parents difficult.

Many biometric measurements of the posterior fossa (PF) and the brain overall are well established in fetal ultrasound (US), but these are not always immediately comparable to fetal MRI measurement - for example biparietal diameter (BPD) is well correlated between MRI and US, whereas lateral ventricle measurements are poorly correlated in late gestation fetuses.(4)(5) Qualitative fetal MRI assessments show correlations with postnatal diagnosis, with up to 93\% diagnostic accuracy in brain anomalies.(6) However, in assessment of fetopathology for individuals with PFAs this is not consistent across diagnoses - vermian hypoplasia and cerebellar hemisphere hypoplasia showed poor agreement between MRI and final diagnosis.(7)

MRI is increasingly used as an antenatal imaging modality, and improves diagnostic accuracy in fetal brain abnormalities in addition to US by $16-22 \% .(8)(9)$ Quantitative assessment may be better than qualitative visual description(10) in predicting outcome, and communicating findings with colleagues and families.

Although magnetic resonance spectroscopy, functional MRI, diffusion-weighted and diffusion tensor imaging and tractography have been used in the research assessment of the fetal brain, (11) this systematic review will focus on morphological assessments, as these are not yet widely used clinically. 
This study aims to identify validated 2D biometric measurements of the PF on fetal MRI and explore whether they can be used to differentiate types of PFA.

\section{Materials and Methods}

Data sources

This systematic review was performed according to an a-priori designed protocol. It was reported according to the Preferred Reporting Items for Systematic Reviews and Meta-Analysis (PRISMA) (12) and Meta-analysis of Observational Studies in Epidemiology (MOOSE) (13) guidelines, and registered with the International Prospective Register of Systematic Reviews (PROSPERO ID CRD42019142162). No ethical approval or patient consent was required. The search was performed in June 2019 via PubMed, Web of Science, UCL MetaLib, Scopus, Mendeley, ProQuest Dissertations/Theses, Cochrane Library, and through citation searching. The search terms were: (newborn OR neonat* OR fetus OR fetal) AND (posterior fossa OR dandy walker OR cerebell* OR brain stem) AND (mri OR magnetic resonance imaging).

\section{cungibility criteria}

Eligible studies included fetuses where T2-weighted MRI PF measurements were performed, in fetuses with and without PFAs. This included measurements used to differentiate normal and abnormal PFs, to determine normal fetal controls, and/or to predict outcome. Measurements included were all measurements of the PF, or other areas of the brain relevant to PFAs.

Studies assessing post-mortem specimens or animals alone were excluded. We did not include other morphological assessments that were not measurements, such as counting lobulation. Also excluded were studies exclusively assessing other forms of MRI assessment, such as diffusion or spectroscopy measurement, or using MRI with additional reconstruction or 
segmentation processing prior to measurements, or other imaging types such as US. However, papers using multiple imaging modalities but including measurements by fetal MRI were included for these measurements only. This was to focus on measurements with most widespread clinical use - for example segmentation is not available in all centres with MRI.

Individual case reports, studies or case series with a sample size of $\leq 3$ cases, and reviews were not included; all other study types were included, including theses and conference abstracts. There was no language restriction. Duplicates were removed. When the same data was used for multiple publications/conference abstracts, the version including the most detail was used.

\section{Study selection}

Titles and abstracts were assessed to select potentially relevant papers, then the full text of these was assessed for eligibility. One reviewer (KM) assessed articles for selection. In five articles where full details were not included, authors of selected articles were contacted for additional information.

\section{unality assessment}

Two reviewers (KM and LS) then separately assessed articles for bias and quality, using the QUADAS-2 (Quality Assessment of Diagnostic Accuracy Studies) tool (14). This recorded whether the study described appropriate patient selection criteria, appropriate and independent reference test and index test, appropriate time period between tests, and blinding of the index test and reference tests. These factors were then used to assess the risk of bias and whether concerns were raised regarding applicability to the review. Disagreements were resolved by consensus. 
Two reviewers (KM and LS) extracted data for analysis with Microsoft Excel (Office 365). Extraction included assessment of details of each study type, patient information including demographics, numbers and diagnoses, MRI methodology, measurements taken, and follow up duration and method if included.

\section{Results}

A total of 804 studies were initially screened and 59 publications were included in the final systematic

review $(15)(16)(17)(18)(19)(20)(21)(22)(23)(24)(25)(7)(26)(5,27)(28)(29)(30)(31)(32)(33)(34)(35)(36)($ $37)(38)(39)(40)(41)(42)(43)(44)(4)(45)(46)(47)(48)(49)(50)(51)(52)(53)(54)(55)(56)(57)(58)(59)(60)(6$ 1)(62)(63)(64)(65)(66)(67)(68)(69) (Fig. 1)(Supplementary Table 1). Separate publications with duplicated data from those included were assessed.(70)(71)(72)(73)(74)(75)(76)(77)(78)(79)(80)(81)

\section{Studies included}

\section{-riGURE 1>}

Studies included CNS (central nervous system) and PF abnormalities such as "Dandy-Walker continuum", Joubert syndrome, megacisterna magna, spina bifida with associated Chiari II malformation, plus small for gestational age (GA) fetuses, twin-twin transfusion syndrome, Down syndrome, congenital heart disease, congenital diaphragmatic hernia, and viral infections (parvovirus and zika). Publications came from 14 countries globally, although USA was the most common country of origin (20/59), and European countries most represented (28/59). 
Quality assessment with QUADAS scoring(14) showed that the majority of studies included had either a high or unclear risk of bias, and high or unclear applicability concerns (Supplementary Table 2). Only six papers had an entirely low risk of bias and low concerns regarding applicability.

\section{MRI methodology and parameters}

The studies assessed measurements on fetal MRI between 13 and 42 weeks of gestation, with median 28 weeks (IQR 23-33 weeks). There was variation in the magnetic field strength used for imaging in the different studies; where described, this varied from 0.5-T (Tesla) to 3-T. There was also variation in slice thickness, from $2.5-10 \mathrm{~mm}$.

All three slice planes were used for measurements - sagittal views in 43 studies, axial views in 28 studies, and coronal views in 17 studies. These included the same measurements in different views. For eight studies, it was not clear which slices were used.

\section{Measurements of the posterior fossa}

Over the 59 studies, 6859 fetuses had 62 different 2D measurements of the PF and related artas (Supplementary Table 3) (Figure 2). These included linear, area and angular measurements, which represent measures of PF size, cerebellum/vermis, brainstem, and some supratentorial measurements. Following the measurements, various further ratios and calculations were performed.

$<$ FIGURE 2>

Nine measurements were evaluated in different planes by different studies - TCD (transverse cerebellar diameter), lateral ventricle transverse diameter, BPD (cerebral, cranial), 
fronto-occipital distance (cerebral, cranial), CM (cisterna magna) depth (craniocaudal), transverse diameter of the PF, and $4^{\text {th }}$ ventricle anteroposterior diameter.

TCD was measured as total, or the right and left hemispheres separately. Cerebellar surface area was total, right and left. Vermis surface area was total, anterior and posterior. Vermis craniocaudal diameter was measured as the total, plus measuring the height above and below the declive line. Cerebral BPD was total, or right and left hemispheres separately. Lateral ventricle measurements were most variable, including right and left ventricle measurements, either including both or the largest measurement only, plus anterior and posterior ventricle measurements.

We assessed the most commonly used measurements by looking at how many studies employed the measurement, and by a total number of fetuses on which the measurement has been performed (Table 1). 11 measurements were used in 10 or more studies and at least 1200 fetuses.

$<$ TABLE 1>

The most frequently used measurement by both assessments was the TCD. Other commonly used linear measures of the PF were of the vermis (craniocaudal diameter, anteroposterior diameter, surface area) and CM depth. The most frequent angle measured was the TVA (tegmento-vermian angle), also known as the brainstem-vermis angle. This was drawn between the dorsal surface of the brainstem and the ventral surface of the vermis, so giving an evaluation of upward rotation of the vermis. The next most common angle was the CSOA (clivussupraoccipital angle). This was the angle between lines drawn on the postero-superior surface of the clivus and the antero-superior surface of the supraocciput, giving an evaluation of PF shape. 
Commonly used measurements of the brainstem and surrounding area were of the pons (anteroposterior and craniocaudal diameters), $3^{\text {rd }}$ ventricle and $4^{\text {th }}$ ventricle.

In the context of PF assessment, there were also supratentorial measurements. The cerebral BPD and cranial BPD, and the cerebral FOD (fronto-occipital distance) and cranial FOD, along with lateral ventricular transverse diameter, were the most frequently used.

\section{Measurements of the posterior fossa-calculations}

Calculations were used to assess measurements in detail in a fifth of studies (13/59). Most commonly, to standardise measures against brain size, such as by creating a ratio with BPD.(18)(43)(25)(56)(54)(57) Calculations were used to assess the symmetry of different brain areas, such as comparing the surface area of the right and left cerebellar hemispheres, or for the vermis, the surface area was compared between the anterior and posterior lobe, or above and below the fastigial-declive line.(4)(7)(47) Calculations were also used to assess other brain features that are harder to measure directly, such as estimates of the CSF space.(24)(56)

Sex effect on fetal measurements was not commonly described. Tilea et al(29) showed a statistically significant difference by sex for the cerebral BPD, TCD and length of the corpus callosum. However, they concluded the small effect size was not clinically significant.

\section{Gestational age}

GA was examined by 35 studies (Figure 3), with 34 measurements shown to correlate positively or negatively with GA in healthy fetuses, including linear, area and angle measurements. Positive correlations with GA were largely seen, with three negatively correlated including $4^{\text {th }}$ 
ventricle angle, cerebellar primary fissure angle, and opercular measurements. The latter was shown to be positively correlated elsewhere however.(39)(18)(51) In total, 15 measurements and six angles (such as TVA) were unaffected by GA. Studies comparing CM depth, lateral ventricle transverse diameter, CSOA, and inferior vermian distance (craniocaudal) with GA have been inconsistent in their findings.(15)(21)(25)(28)(63)(18)(51)(54)(61)(44)(19)(26)(39)(52)

\section{$<$ FIGURE 3>}

\section{Diagnosis}

23 studies looked at the diagnostic use of measurements (Table 2), however interpretation was hampered by varying use of definitions and terminology, despite a drive towards anatomical descriptions.(18) TCD, vermis measurements, CM depth, brainstem/vermis angles, BPD and $4^{\text {th }}$ ventricular measurements were most commonly performed.

\section{$<$ TABLE 2>}

For five studies, this assessment compared a group of quite varied CNS abnormalities generally,(16)(22)(23)(15)(82) including PFAs. Only TVA was found to be correlated with this wide selection of diagnoses in more than one study.

Six studies looked at a diverse group of PFAs(4)(83)(47)(39)(7)(26) and compared these to controls. PFAs reported included abnormalities of the cerebellum, vermis, brainstem and cisterna magna, and cysts. Measures correlating with PFA diagnosis in more than one paper included TCD, vermis craniocaudal diameter, vermis anteroposterior diameter, vermis SA, IVD (inferior vermian distance (anteroposterior)) and CM depth. 
Two papers looked at specific CNS diagnoses only, such as "Dandy-Walker malformation" or continuum, or Joubert syndrome. For these, more specific measurements proved different between the cohort and controls - PF surface area and vermis surface area for a Dandy-Walker typediagnosis,(36) and TCD, vermis craniocaudal measurement, CM depth, and calculations using the IPF (interpeduncular fossa) for Joubert syndrome.(30) These measures make sense as useful quantitative diagnostic tools in relation to the anatomy of these conditions. In particular, Joubert syndrome was only explicitly included in one other study,(23) where TVA was correlated with pathology. For this rare condition, although measures of the IPF were only performed in a small number of fetuses, as a relevant feature for the condition, this could still be most clinically useful. Six studies looked at measures of the PF to diagnose neural tube defects, using a variety of different measures.(24)(32)(37)(44)(56)(63) Four of these studies went on to look at measures that differed within the neural tube defect group, including differentiating between open and closed defects, and looking at the changes pre- and post-operatively in fetal repair, and between fetal and postnatal repair cohorts. Within these studies, the CSOA, lateral ventricle transverse diameter, transverse diameter of the PF, and PF surface area were used more than once. Since the imuroduction of in-utero repair for neural tube defects,(84) clarity of assessment on MRI has become more crucial - the initial study used only qualitative measures of the PF. These results suggest simple measurements could be of benefit in this context.

Four studies showed measurements of the PF correlated with a diagnosis of more systemic abnormalities compared to controls - congenital heart disease,(85) Down syndrome(66) and fetuses small for GA.(33)(86)

Two other studies looked at measures for distinguishing within diagnostic groups. One looked at the differences between the donor and recipient twins within twin-twin transfusion syndrome - here TCD, cranial BPD and HC differed between the groups.(57) The other looked at 
fetuses with congenital diaphragmatic hernias, with vermis anteroposterior diameter measurements significantly different between infants who survived to discharge and those who died.(67)

\section{Developmental outcomes}

Eight studies examined neurodevelopmental outcomes. Only four assessed the relationship between measurements and outcome (Table 3),(43)(85)(52)(55) with varied developmental assessments,(87)(88)(89) with the remaining four examining outcome in relation to specific diagnoses,(39)(59) or describing the range of outcomes seen.(34)(41) 8 measurements correlated with outcome, and only 3 of these in the context of PFAs - vermis craniocaudal diameter, IVD, and CM depth. Only the latter was from a study showing a specific link between a PFA, enlarged cisterna magna, with outcome.(55)

$<$ TABLE 3>

\section{Liscussion}

This is the first systematic review to assess 2D biometric measurements currently used for assessing the PF on fetal MRI, and how these have been used for diagnosis and relation to developmental outcomes. Our findings showed 62 different measurements currently used, including linear, area and angular measurements. These represent measures of the PF, cerebellum/vermis, brainstem, as well as supratentorial measurements. Despite the broad range of measurements, we show how few have been compared to later outcomes - only eight studies considered this area. 
The use of qualitative assessments alone of the PF in fetal MRI should no longer be common practice - qualitative assessments are not completely accurate(7), and quantitative measurements can be combined with qualitative for a more thorough assessment $(26)(20)(62)(37)(50)(90)$. The development of centile calculators (54) should make the use of quantitative measures easier. We demonstrate here the variety of measurements currently used globally, without each adding to the diagnostic picture - consistency in use is needed to standardise the evaluation of images.

\section{Implications for clinical practice}

From the literature available, we propose the following flowchart for validated 2-

dimensional measurements of the PF (Fig. 4). For a routine fetal MRI where an assessment of the PF is being made, 16 measurements will provide an ample evaluation, both looking at the PF and its components, as well as an assessment of the brain as a whole as a comparison. These measurements will be sufficient to highlight the most common PFAs. We propose this tool as a diagnostic tool, with suggested measurements, although not all will be possible in all patients, for example due to gestation and optimal views.

\section{$<$ FIGURE 4>}

The definitions used for PFAs are variable, as they are numerous and difficult to classify.

However, most can be divided into those with cranial vault malformations and hindbrain malformations, with the latter further divided into those with increased fluid-filled space in the PF, and cerebellar or vermian agenesis, aplasia or hypoplasia.(91)(92)(93)(94)(95)(96) It is not possible to cover all PFAs, but here we cover some of the most common and the useful measurement findings. 
Megacisterna magna, also known as enlarged $\mathrm{CM}$, is the presence of increased fluid spaces, with a normal tentorium and cerebellum/brainstem. By measurements, this would be an increased CM, with otherwise normal measurements. A "Blake's Pouch cyst" includes additional abnormal measurements, with an increased TVA, IVD, occipital angle and $4^{\text {th }}$ ventricle diameters. With an arachnoid cyst, there may simply be an increased CM depth, but when very enlarged, dimensions of the vermis/cerebellum and brainstem may be reduced by mass effect. There may also be hydrocephalus with changes to the lateral ventricle transverse diameter.

If the CM depth, TVA, occipital angle and IVD are increased, but there are also abnormalities of the TCD, vermis craniocaudal diameter/anteroposterior diameter/surface area, then other pathology must be considered. This can include a focal abnormality such as dysplasia or as a result of previous insult (ischaemia, haemorrhage) - for these there could be unilateral abnormalities, so variations of the routine measures may be needed, such as measuring the TCD for each cerebellar hemisphere separately.

The "Dandy-Walker" malformation/variant/continuum definition becomes even more unclear, with a range including the "inferior vermian hypoplasia". The following measurements cuuld be abnormal: TCD, vermis craniocaudal diameter/anteroposterior diameter/surface area, TVA, CM depth, IVD, $4^{\text {th }}$ ventricle laterolateral diameter, lateral ventricles, occipital angle.

A small number of scenarios will then need specific measurements for further assessment. For these more particular situations, there are often fewer studies, so although measures may be less frequently used overall these measures are more likely to help with a certain diagnosis.

Neural tube defects cause changes in the PF through a Chiari II malformation. In this scenario, additional measurements will allow specific changes to be monitored. These include the cerebellar herniation level and brainstem kinking level, both of which are not of use to measure in most clinical situations. 
A less common scenario is investigation for possible Joubert syndrome and related disorders. The classic MRI description of the "molar tooth sign"(97) can be assessed in a quantitative way through specific measures of these features.

\section{Implications for research}

The diversity and variation in 2D biometric measurements used to assess the PF on fetal MRI highlights the need for standardisation of the measurements used in clinical and research settings. Prospective studies are needed, using standardised measurements and comparing to developmental outcomes. This will improve the accuracy of antenatal diagnoses and prognoses given to families.

\section{Other clinical concerns}

Fetal MRIs in this review were performed across the second and third trimesters. There is some concern regarding MRI scanning in early pregnancy. This is not related to safety concerns,(98) but primarily due to technical difficulty with fetal movement and limited diagnostic value,(99)(100) Iv example early assessment of the PF on MRI may lead to false positive diagnoses (101). However, legal limits on the timing of pregnancy termination in some countries means clinical information is needed in a timely manner for these difficult decisions to be discussed.

MRI field strength was also variable across the studies. Safety guidance varies regarding maximal field strengths,(100) although advice is for considerations of the risks and benefits for each patient.(99)(102) 
The strengths of this systematic review were the robust methodology for identifying studies for inclusion, assessment of data quality, and synthesis of data.

Due to the nature of the question, there was a significant degree of potential bias, with all studies being observational in approach. Another common source of bias was a lack of blinding of those performing measurements and other assessments. Many studies were also small sizes -17 studies included less than 50 patients, and 5 studies included less than 10 patients.

Discrepancy and variation in imaging techniques meant the accuracy of measurements was likely to be different between studies. This variation in methodology, along with the small numbers of studies assessing outcomes, meant no meta-analysis was possible.

Despite approaching authors of publications/conference abstracts that provided only minimal details of relevant studies, not all responded, so additional data may have been missed. There may also be publication bias in the available studies.

\section{Conclusion}

In summary, 62 2D biometric measurements have been used to assess the PF on fetal MRI. mese included measures of the PF directly, and of other brain structures relevant to the PF. They have been used in a range of GAs and settings, both to identify normal growth and in the diagnosis of multiple pathologies. These included linear measurements, surface area measurements and angles. Many of them assessed similar features in slightly different ways. Although many measures have been used, those found to be valuable most consistently within the literature are starting to emerge. We propose 16 measurements for all individuals, followed by additional measures in the case of Joubert syndrome and neural tube abnormalities. 
This study provides a summary of the various measures of the PF on fetal MRI currently in use. We hope this will enable more consistency in usage, both clinically and for research, to streamline the measurements required for diagnostic and prognostic purposes. 


\section{References}

1. Garel C, Fallet-Bianco C, Guibaud L. The fetal cerebellum: Development and common malformations. In: Journal of Child Neurology. 2011. p. 1483-92.

2. Rutherford MA. Magnetic resonance imaging of the fetal brain. 2009;

3. Limperopoulos C, Robertson RL, Khwaja OS, Robson CD, Estroff JA, Barnewolt C, et al. How accurately does current fetal imaging identify posterior fossa anomalies? Am J Roentgenol. 2008;190(6):1637-43.

4. Ber R, Bar-Yosef O, Hoffmann C, Shashar D, Achiron R, Katorza E. Normal fetal posterior fossa in MR imaging: New biometric data and possible clinical significance. Am J Neuroradiol. 2015;36(4):795-802.

5. Hatab MR, Zaretsky M V., Alexander JM, Twickler DM. Comparison of fetal biometric values with sonographic and 3D reconstruction MRI in term gestations. Am J Roentgenol. 2008;191(2):340-5.

6. Griffiths PD, Bradburn M, Campbell MJ, Cooper CL, Graham R, Jarvis D, et al. Use of MRI in the diagnosis of fetal brain abnormalities in utero (MERIDIAN): a multicentre, prospective cohort study. Lancet [Internet]. 2017;389(10068):538-46. Available from: http://dx.doi.org/10.1016/S0140-6736(16)31723-8

7. Tilea B, Delezoide AL, Khung-Savatovski S, Guimiot F, Vuillard E, Oury JF, et al. Comparison between magnetic resonance imaging and fetopathology in the evaluation of fetal posterior fossa non-cystic abnormalities. Ultrasound Obstet Gynecol. 2007;29(6):651-9.

8. Jarvis D, Mooney C, Cohen J, Papaioannou D, Bradburn M, Sutton A, et al. A systematic review and meta-analysis to determine the contribution of MR imaging to the diagnosis of foetal brain abnormalities in utero. Eur Radiol. 2017;

9. Griffiths PD, Brackley K, Bradburn M, Connolly DJA, Gawne-Cain ML, Kilby MD, et al. 
Anatomical subgroup analysis of the MERIDIAN cohort: posterior fossa abnormalities.

Ultrasound Obstet Gynecol. 2017;50(6):745-52.

10. Adamsbaum C, Moutard ML, André C, Merzoug V, Ferey S, Quéré MP, et al. MRI of the fetal posterior fossa. Pediatr Radiol. 2005;35(2):124-40.

11. Jakab A, Pogledic I, Schwartz E, Gruber G, Mitter C, Brugger PC, et al. Fetal Cerebral Magnetic Resonance Imaging Beyond Morphology. Semin Ultrasound, CT MRI [Internet]. 2015;36(6):465-75. Available from: http://dx.doi.org/10.1053/j.sult.2015.06.003

12. Moher D, Liberati A, Tetzlaff J, Altman DG. Preferred reporting items for systematic reviews and meta-analyses: the PRISMA statement. J Clin Epidemiol. 2009;62(10):1006-12.

13. Stroup DF, Berlin JA, Morton SC, Olkin I, Williamson GD, Rennie D, et al. Meta-analysis of observational studies in epidemiology: A proposal for reporting. J Am Med Assoc. 2000;

14. Whiting PF, Rutjes AWS, Westwood ME, Mallet S, Deeks JJ, Reitsma JB, et al. QUADAS-2: A Revised Tool for the Quality Assessment of Diagnostic Accuracy Studies. Ann Intern Med. 2011;154(4):253-60.

15. Twickler DM, Reichel T, Mclntire DD, Magee KP, Ramus RM. Fetal central nervous system ventricle and cisterna magna measurements by magnetic resonance imaging. Am J Obstet Gynecol. 2002;187(4):927-31.

16. Reichel TF, Ramus RM, Caire JT, Hynan LS, Magee KP, Twickler DM. Fetal Central Nervous System Biometry on MR Imaging. AJR Am J Roentgenol. 2003;180(April):1155-8.

17. Robinson A, Blaser S, Toi A, Chitayat D, Gundogan M, Laughlin S, et al. MR Imaging of the Fetal Cerebellar Vermis in Utero : Description of some Useful Anatomical Criteria for Normal Development. In: Radiological Society of North America 2003 Scienti. 2003.

18. Garel C. MRI of the Fetal Brain. Berlin, Heidelberg: Springer Berlin Heidelberg; 2004.

19. Read C, Ramus RM, McIntire DD, Twickler DM. Using fetal MRI to define normal 
development of the cerebellum and vermis. In: SMFM. 2004.

20. Triulzi F, Parazzini C, Righini A. MRI of fetal and neonatal cerebellar development. Seminars in Fetal and Neonatal Medicine. 2005.

21. Twickler DM. Fetal growth and development of the posterior fossa and vermis with magnetic resonance imaging. In: 13th World Congress on Ultrasound in Obstetrics and Gynaecology. 2005.

22. Robinson A, Blaser S, Toi A, Chitayat D, Pantazi S, Halliday W, et al. Sonographic morphology of the fetal fourth ventricle, cerebellar vallecula and Blake's pouch - potential prognosticators in abnormalities of vermian development. Ultrasound Obstet Gynecol. 2006;28:436.

23. Robinson A, Blaser S, Toi A, Pantazi S, Chitayat D, Ryan G. Developmental anatomy and morphology of the cerebellar vermis - essential knowledge for the imaging assessment of posterior fossa anomalies. Ultrasound Obstet Gynecol. 2006;28:375.

24. Danzer E, Johnson MP, Bebbington M, Simon EM, Wilson RD, Bilaniuk LT, et al. Fetal head biometry assessed by fetal magnetic resonance imaging following in utero myelomeningocele repair. Fetal Diagn Ther. 2007;22(1):1-6.

25. Manganaro L, Perrone A, Savelli S, Di Maurizio M, Maggi C, Ballesio L, et al. Evaluation of normal brain development by prenatal MR imaging. Radiol Medica. 2007;112(3):444-55.

26. Twickler DM, C.P.Read, Dashe JS. Quantitative and qualitative vermis and posterior fossa evaluation by magnetic resonance imaging in fetuses with suspected abnormal findings by ultrasound examination. Ultrasound Obstet Gynecol. 2007;30:372.

27. Hatab MR, Kamourieh SW, Twickler DM. MR volume of the fetal cerebellum in relation to growth. J Magn Reson Imaging. 2008;27(4):840-5.

28. Parazzini C, Righini A, Rustico M, Consonni D, Triulzi F. Prenatal magnetic resonance imaging: 
Brain normal linear biometric values below 24 gestational weeks. Neuroradiology. 2008;50(10):877-83.

29. Tilea B, Alberti C, Adamsbaum C, Armoogum P, Oury JF, Cabrol D, et al. Cerebral biometry in fetal magnetic resonance imaging: New reference data. Ultrasound Obstet Gynecol. 2009;33(2):173-81.

30. Saleem SN, Zaki MS. Role of MR imaging in prenatal diagnosis of pregnancies at risk for Joubert Syndrome and related cerebellar disorders. Am J Neuroradiol. 2010;31(3):424-9.

31. Canto Moreira N, Teixeira J, Themudo R, Amini H, Axelsson O, Raininko R, et al. Measurements of the normal fetal brain at gestation weeks 17 to 23: A MRI study. Neuroradiology. 2011;53(1):43-8.

32. Steinwendner SL, Bettelheim D, Kasprian G, Brugger PC, Prayer D. Potential prognostic parameters of the Chiari II malformation. Ultrasound Obstet Gynecol. 2011;38(S1):96-96.

33. Damodaram M, Mellisa. Brain development in fetal growth restriction: A volumetric approach using fetal MRI. Imperial College London; 2012.

34. Guibaud L, Larroque A, Ville D, Sanlaville D, Till M, Gaucherand P, et al. Prenatal diagnosis of “isolated" Dandy-Walker malformation: Imaging findings and prenatal counselling. Prenat Diagn. 2012;32(2):185-93.

35. Scott JA, Hamzelou KS, Rajagopalan V, Habas PA, Kim K, Barkovich AJ, et al. 3D morphometric analysis of human fetal cerebellar development. Cerebellum. 2012;11(3):761-70.

36. Wong AM, Bilaniuk LT, Zimmerman RA, Liu PL. Prenatal MR imaging of Dandy-Walker complex: Midline sagittal area analysis. Eur J Radiol. 2012;81(1):e26-30.

37. Abele TA, Lee SL, Twickler DM. MR imaging quantitative analysis of fetal chiari II malformations and associated open neural tube defects: Balanced SSFP versus half-fourier RARE and interobserver reliability. J Magn Reson Imaging. 2013;38(4):786-93. 
38. Qi L, Zhang J. MRI evaluation of normal fetal posterior fossa structures. Chinese J Interv Imaging Ther. 2013;10(8):473-6.

39. Vatansever D, Kyriakopoulou V, Allsop JM, Fox M, Chew A, Hajnal J V., et al. Multidimensional analysis of fetal posterior fossa in health and disease. Cerebellum. 2013;12(5):632-44.

40. Farinha C, Tavares Ó. Development and measurement of the transverse diameter of the fetal cerebellum by MRI. SAÚDE Tecnol. 2014;T2:39-42.

41. Massoud M, Cagneaux M, Garel C, Varene N, Moutard ML, Billette T, et al. Prenatal unilateral cerebellar hypoplasia in a series of 26 cases: Significance and implications for prenatal diagnosis. Ultrasound Obstet Gynecol. 2014;44(4):447-54.

42. Nasiadko C, Scheer I, Meuli M, Moehrlen U, Oschsenbein N. Fetal Brain Morphology After in Utero Repair of Open Neural Tube Defects. In: Neuroradiologicum XXth Symposium. 2014.

43. Sanz-Cortes M, Egaña-Ugrinovic G, Zupan R, Figueras F, Gratacos E. Brainstem and cerebellar differences and their association with neurobehavior in term small-for-gestational-age fetuses assessed by fetal MRI. Am J Obstet Gynecol. 2014;210(5):452.e1-452.e8.

44. Woitek R, Dvorak A, Weber M, Seidl R, Bettelheim D, Schöpf V, et al. MR-based morphometry of the posterior fossa in fetuses with neural tube defects of the Spine. PLoS One. $2014 ; 9(11)$.

45. Frick N, Fazelnia C, Kanzian K, Hitzl W, Fischer T, Forstner R, et al. The reliability of fetal MRI in the assessment of brain malformations. Fetal Diagn Ther. 2015;37(2):93-101.

46. Stamoulis C, Levine D, Feldman H, Parad R, Estroff J. Correlation of fetal cerebellar measurements on US and MRI. Pediatr Radiol. 2015;45(S1):1-246.

47. Goncalves L, Jain S, Krishnan A, Yuxiang Z, Bloom D, Lee W, et al. Quantitative MR Assessment of the Fetal Posterior Fossa: Reproducibility, Reference Ranges and Diagnostic Performance. Pediatr Radiol. 2016;46(S1):1-372. 
48. Katorza E, Bertucci E, Perlman S, Taschini S, Ber R, Gilboa Y, et al. Development of the fetal vermis: New biometry reference data and comparison of 3 diagnostic modalities-3d ultrasound, 2d ultrasound, and mr imaging. Am J Neuroradiol. 2016;37(7):1359-66.

49. Nagaraj UD, Bierbrauer KS, Peiro JL, Kline-Fath BM. Differentiating closed versus open spinal dysraphisms on fetal MRI. Am J Roentgenol. 2016;207(6):1316-23.

50. Pier DB, Gholipour A, Afacan O, Velasco-Annis C, Clancy S, Kapur K, et al. 3D Super-Resolution Motion-Corrected MRI: Validation of Fetal Posterior Fossa Measurements. J Neuroimaging. 2016;26(5):539-44.

51. Wong A, Chavez T, Lai H, Paquette L, Panigrahy A. Synchronous aberrant cerebellar and opercular development in fetuses and neonates with congenital heart disease. J Investig Med. 2016;

52. Xi Y, Brown E, Bailey A, Twickler DM. MR imaging of the fetal cerebellar vermis: Biometric predictors of adverse neurologic outcome. J Magn Reson Imaging. 2016;44(5):1284-92.

53. Jowett V. Brain Growth and Development in Fetuses with Congenital Heart Disease. Imperial College London; 2017.

Kyriakopoulou V, Vatansever D, Davidson A, Patkee P, Elkommos S, Chew A, et al. Normative biometry of the fetal brain using magnetic resonance imaging. Brain Struct Funct. 2017;222(5):2295-307.

55. Liu Z, Han J, Fu F, Liu J, Li R, Yang X, et al. Outcome of isolated enlarged cisterna magna identified in utero: experience at a single medical center in mainland China. Prenat Diagn. 2017;37(6):575-82.

56. Rethmann C, Scheer I, Meuli M, Mazzone L, Moehrlen U, Kellenberger CJ. Evolution of posterior fossa and brain morphology after in utero repair of open neural tube defects assessed by MRI. Eur Radiol. 2017; 
57. Taylor-clarke MC. The fetal brain in co-twins treated for twin-twin transfusion syndrome. Imperial College London; 2017.

58. Castro JDV de, Pereira LP, Dias DA, Aguiar LB, Maia JCN, Costa JIF da, et al. Presumed Zika virus-related congenital brain malformations: the spectrum of CT and MRI findings in fetuses and newborns. Arq Neuropsiquiatr. 2017;

59. Ben-Sira L, Shperling R, Malinger G. Developmental Outcome in fetuses diagnosed with Isolated Vermis abnormality. Child's Nerv Syst. 2018;34(10):2027.

60. Chapman T, Menashe SJ, Zare M, Alessio AM, Ishak GE. Establishment of normative values for the fetal posterior fossa by magnetic resonance imaging. Prenat Diagn. 2018;38(13):1035-41.

61. Conte G, Milani S, Palumbo G, Talenti G, Boito S, Rustico M, et al. Prenatal brain MR imaging: Reference linear biometric centiles between 20 and 24 gestational weeks. Am J Neuroradiol. 2018;39(5):963-7.

62. Zhao D, Cai A, Zhang J, Wang Y, Wang B. Measurement of normal fetal cerebellar vermis at 24-32 weeks of gestation by transabdominal ultrasound and magnetic resonance imaging: A prospective comparative study. Eur J Radiol. 2018;100(36):30-5.

63. Aertsen M, Verduyckt J, De Keyzer F, Vercauteren T, Van Calenbergh F, De Catte L, et al. Reliability of MR imaging-based posterior fossa and brain stem measurements in open spinal dysraphism in the era of fetal surgery. Am J Neuroradiol. 2019;40(1):191-8.

64. Blondiaux E, Valence S, Friszer S, Rodriguez D, Burglen L, Ducou Le Pointe H, et al. Prenatal Imaging Findings of Pontine Tegmental Cap Dysplasia: Report of Four Cases. Fetal Diagn Ther. 2019;45(3):197-204.

65. Maisonneuve E, Garel C, Friszer S, Pénager C, Carbonne B, Pernot F, et al. Fetal Brain Injury Associated with Parvovirus B19 Congenital Infection Requiring Intrauterine Transfusion. Fetal 
Diagn Ther. 2018;

66. Patkee PA, Baburamani AA, Kyriakopoulou V, Davidson A, Avini E, Dimitrova R, et al. Early alterations in cortical and cerebellar regional brain growth in Down Syndrome: An in-vivo fetal and neonatal MRI assessment. Neurolmage Clin. 2019;25(2020):102139.

67. Radhakrishnan R, Merhar SL, Burns P, Zhang B, Lim FY, Kline-Fath BM. Fetal brain morphometry on prenatal magnetic resonance imaging in congenital diaphragmatic hernia. Pediatr Radiol. 2019;49:217-23.

68. Spinelli M, Wiest R, Di Meglio L, Baumann M, Raio L, Surbek D. The "vermian-crest angle": does it allow accurate categorisation of fetal upward rotation of cerebellar vermis on intrauterine MRI? A pilot study. Clin Radiol. 2019;74(6):489.e1-489.e7.

69. Rehder R, Yang E, Cohen AR. Variation of the slope of the tentorium during childhood. Child's Nerv Syst. 2016;32(3):441-50.

70. Patkee P, Davidson A, Kyriakopoulou V. Early alterations in cortical and cerebellar regional brain growth in Down Syndrome : An in-vivo fetal and neonatal MRI assessment. bioRxiv. 2019;(June).

Garel C, Chantrel E, Elmaleh M, Brisse H, Sebag G. Fetal MRI: Normal gestational landmarks for cerebral biometry, gyration and myelination. Child's Nerv Syst. 2003;19(7-8):422-5.

72. Damodaram MS, Story L, Eixarch E, Patkee P, Patel A, Kumar S, et al. Foetal volumetry using Magnetic Resonance Imaging in intrauterine growth restriction. Early Hum Dev. 2012;88:S35-40.

73. Woitek R, Kasprian G, Weber M, Asenbaum U, P. Berzaczy D, Kulemann V, et al. Measurements of the posterior fossa on fetal MRI in open and closed neural tube defects. $2001 ; 43$.

74. Ber R, Hoffmann C, Shashar D, Bar-Yosef O, Konen E, Achiron R, et al. Normal fetal posterior 
fossa in magnetic resonance imaging: new biometric reference data and possible clinical significance. Ultrasound Obstet Gynecol. 2014;44(Suppl.1):322.

75. Parad RE, Stamoulis C, Levine D, Feldman H, Parad RB, Estroff JA. Correlation between ultrasound and MRI measurements of the fetal cerebellum performed on the same day. Ultrasound Obstet Gynecol. 2017;50(Suppl. 1):264.

76. Katorza E, Bertucci E, C.Hoffmann, Y.Gilboa, Achiron R. Vermian biometry in normal fetal posterior fossa: comparing 3D ultrasonographic method measurements with 2D ultrasonographic method and magnetic resonance imaging. Ultrasound Obstet Gynecol. 2012;40(Suppl. 1):219-20.

77. Wong A, Chavez T, Lai H, Paquette L, Panigrahy A. Synchronous aberrant cerebellar and opercular development in fetuses and neonates with congenital heart disease. J Investig Med. 2016;64:317.

78. Wong A, O’Neil S, Chavez T, Lai H, Panigrahy A, Paquette L. Serial cerebellar and opercular structural development of fetuses and neonates with congenital heart disease (CHD) correlated with early neurodevelopmental outcomes. J Investig Med. 2016;64:317-8. Taylor-Clarke M, Allsop JM, McGuinness A, Wimalasundera RC, Gardiner HM, Rutherford MA. Twin-twin transfusion syndrome: fetal MRI measurement of intrapair differences in brain biometry. Arch Dis Child Fetal Neonatal Ed. 2011;96(Suppl 1):Fa70.

80. Zare M, Chapman T, Menashe S, Alessio A, Ishak G. Establishment of normative values for the fetal posterior fossa by MRI. Pediatr Radiol. 2018;48(Suppl 1):S142.

81. Radhakrishnan R, Merhar S, Burns P, Zhang B, Lim F-Y, Kline-Fath B. Fetal MRI Assessment of Prenatal Brain Injury in Congenital Diaphragmatic Hernia. Pediatr Radiol. 2017;47(Suppl 1):S91.

82. Paladini D, Volpe P. Posterior fossa and vermian morphometry in the characterization of fetal 
cerebellar abnormalities: A prospective three-dimensional ultrasound study. Ultrasound Obstet Gynecol. 2006;27(5):482-9.

83. Spinelli M, Wiest R, Di Meglio L, Baumann M, Raio L, Surbek D. The "vermian-crest angle": does it allow accurate categorisation of fetal upward rotation of cerebellar vermis on intrauterine MRI? A pilot study. Clin Radiol. 2019;74(6):489.e1-489.e7.

84. Adzick N, Thom E, Spong C, Brock III J, Burrows, PK, Johnson M, Howell L, et al. A Randomized Trial of Prenatal versus Postnatal Repair of Myelomeningocele. N Engl J Med. 2011;364(11):993-1004.

85. Wong A, Chavez T, Lai H, Paquette L, Panigrahy A. Synchronous aberrant cerebellar and opercular development in fetuses and neonates with congenital heart disease. J Investig Med. 2016;64(1):317.

86. Sanz-Cortes M, Egaña-Ugrinovic G, Zupan R, Figueras F, Gratacos E. Brainstem and cerebellar differences and their association with neurobehavior in term small-for-gestational-age fetuses assessed by fetal MRI. Am J Obstet Gynecol. 2014;

87. Noble Y. BRN. The clinimetric properties of neonatal neurobehavioural assessments for the premature infant up to 4 months: A systematic review. Dev Med Child Neurol. 2009;

88. Ball RS. The Gesell developmental schedules: Arnold Gesell (1880-1961). J Abnorm Child Psychol. 1977;5(3):233-9.

89. Newborg J. Battelle developmental inventory. 2nd ed. Itasca, IL: Riverside Publishing; 2005.

90. Grossman R, Hoffman C, Mardor Y, Biegon A. Quantitative MRI measurements of human fetal brain development in utero. Neuroimage. 2006;33(2):463-70.

91. Guibaud L, des Portes V. Plea for an anatomical approach to abnormalities of the posterior fossa in prenatal diagnosis. Ultrasound Obstet Gynecol. 2006;27(5):477-81.

92. Cotes C, Bonfante E, Lazor J, Jadhav S, Caldas M, Swischuk L, et al. Congenital basis of 
posterior fossa anomalies. Neuroradiol J. 2015;28(3):238-53.

93. Robinson AJ. Inferior vermian hypoplasia - Preconception, misconception. Ultrasound Obstet Gynecol. 2014;43(2):123-36.

94. Garel C. Posterior fossa malformations: main features and limits in prenatal diagnosis. Pediatr Radiol. 2010;40(6):1038-45.

95. Chapman T, Mahalingam S, Ishak GE, Nixon JN, Siebert J, Dighe MK. Diagnostic imaging of posterior fossa anomalies in the fetus and neonate: Part 1, normal anatomy and classification of anomalies. Clinical Imaging. 2015.

96. Chapman T, Mahalingam S, Ishak GE, Nixon JN, Siebert J, Dighe MK. Diagnostic imaging of posterior fossa anomalies in the fetus and neonate: Part 2, posterior fossa disorders. Clinical Imaging. 2015.

97. Maria BL, Hoang KBN, Tusa RJ, Mancuso AA, Hamed LM, Quisling RG, et al. "Joubert syndrome" revisited: Key ocular motor signs with magnetic resonance imaging correlation. J Child Neurol. 1997;

98. Levine D. Timing of MRI in pregnancy, repeat exams, access, and physician qualifications. Semin Perinatol. 2013;37(5):340-4.

99. Wataganara T, Ebrashy A, Aliyu LD, Moreira De Sa RA, Pooh R, Kurjak A, et al. Fetal magnetic resonance imaging and ultrasound. J Perinat Med. 2016;44(5):533-42.

100. Prayer D, Malinger G, Brugger PC, Cassady C, De Catte L, De Keersmaecker B, et al. ISUOG Practice Guidelines: performance of fetal magnetic resonance imaging. Ultrasound Obstet Gynecol. 2017;49(5):671-80.

101. Pinto J, Paladini D, Severino M, Morana G, Pais R, Martinetti C, et al. Delayed rotation of the cerebellar vermis: a pitfall in early second-trimester fetal magnetic resonance imaging. Ultrasound Obstet Gynecol. 2016;48(1):121-4. 
102. The Society and College of Radiographers/British Association of Magnetic Resonance Radiographers. MRI Safety Guidance Document. 2016;1-32.

\section{Figure/table legends}

Figure 1. Flow chart of study selection process.

Figure 2. Diagrams of measurements taken - sagittal, axial and coronal slices.

1. Vermis craniocaudal diameter, 2. Vermis anteroposterior diameter, 3. Pons anteroposterior diameter, 4. Pons craniocaudal diameter, 5. Clivus-supraoccipital angle, 6. Fourth ventricle anteroposterior diameter, 7. Vermis surface area, 8. Occipital angle, 9. Foramen magnum anteroposterior diameter, 10. Cerebellar herniation level, 11. Posterior fossa surface area, 12.

Fronto-occipital distance skull, 13. Fronto-occipital distance brain, 14. Tegmento-vermian angle, 15. mijerior vermian distance, 16. Lateral ventricle transverse diameter, 17. Biparietal diameter skull, 18. Biparietal diameter brain, 19. Interpeduncular fossa anteroposterior diameter, 20. Midbrain/isthmus anteroposterior diameter, 21. Fourth ventricle lateral diameter, 22. Cerebellar surface area, 23. Cisterna magna depth, 24. Transcerebellar diameter, 25. Transverse diameter of the posterior fossa

Figure 3. Measurements correlated or unchanged with gestational age.

Figure 4. Diagram of which measurements to take in different clinical scenarios - all fetuses should have the first measurements taken, with the additional measurements as required. 
Table 1. Measurements taken, by most common.

Table 2. Measurements distinguishing a diagnosis from control.

CM (cisterna magna), CNS (central nervous system), CSF (cerebrospinal fluid), CSOA (clivus supraoccipital angle), HC (head circumference), IVD (inferior vermian distance (anteroposterior)), PFA (posterior fossa abnormalities), SA (surface area), TCD (transverse cerebellar diameter), TVA (tegmento-vermian angle)

Table 3. Measurements associated with outcomes.

CM (cisterna magna), GA (gestational age), IVD (inferior vermian distance (anteroposterior)), MRI (magnetic resonance imaging), SGA (small for gestational age)

\section{Appendices}

Supplementary Table 1. Publications included in final systematic review.

$B P D$ (biparietal diameter), CNS (central nervous system), FOD (fronto-occipital diameter), HC (head circumference), IVD (inferior vermian distance (anteroposterior)), MRI (magnetic resonance imaging), PFA (posterior fossa), PFA (posterior fossa abnormality), SGA (small for gestational age),

$\varkappa D$ (transverse cerebellar diameter), TVA (tegmento-vermian angle), US (ultrasound)

Supplementary Table 2. Quality assessment of included publications using QUADAS2.

Supplementary Table 3. Full table of measurements taken in each study. 
Table 1. Measurements taken, by most common.

\begin{tabular}{|c|c|c|}
\hline Measurement & $\begin{array}{l}\text { Frequency by } \\
\text { studies - number } \\
\text { (percentage of } \\
\text { total) }\end{array}$ & $\begin{array}{l}\text { Frequency by } \\
\text { fetus numbers - } \\
\text { number } \\
\text { (percentage of } \\
\text { total) }\end{array}$ \\
\hline Transcerebellar diameter & $37(63 \%)$ & $4007(58 \%)$ \\
\hline Vermis craniocaudal diameter & $31(53 \%$ & $3760(55 \%)$ \\
\hline Vermis anteroposterior diameter & $22(37 \%)$ & $2927(43 \%)$ \\
\hline teral ventricle transverse diameter & $17(29 \%)$ & 2017 (29\%) \\
\hline ain biparietal diameter & $16(27 \%)$ & $1968(29 \%)$ \\
\hline Vermis surface area & $15(25 \%)$ & $2228(32 \%)$ \\
\hline ull biparietal diameter & $14(24 \%)$ & $1885(27 \%)$ \\
\hline terna magna depth & $13(22 \%)$ & $1249(18 \%)$ \\
\hline Brain fronto-occipital distance & $11(19 \%)$ & $1407(21 \%)$ \\
\hline Pons anteroposterior diameter & $10(17 \%)$ & $1823(27 \%)$ \\
\hline Tegmento-vermian angle (or brainstem vermis angle) & $10(17 \%)$ & $1317(19 \%)$ \\
\hline Skull fronto-occipital distance & $9(15 \%)$ & $1568(23 \%)$ \\
\hline cad circumference & $8(14 \%)$ & $778(11 \%)$ \\
\hline 4th ventricle anteroposterior diameter & $5(8 \%)$ & $521(8 \%)$ \\
\hline Corpus callosum length & $5(8 \%)$ & $1121(16 \%)$ \\
\hline $\begin{array}{l}\text { Inferior vermian distance (or pontocerebellar gap width) } \\
\text { (craniocaudal) }\end{array}$ & $5(8 \%)$ & $460(7 \%)$ \\
\hline . ansverse diameter of the posterior fossa & $5(8 \%)$ & $918(13 \%)$ \\
\hline 4 th ventricle lateral diameter & $4(7 \%)$ & $220(3 \%)$ \\
\hline Givus-supraoccipital angle & $4(7 \%)$ & $844(12 \%)$ \\
\hline sterior fossa surface area & $4(7 \%)$ & $566(8 \%)$ \\
\hline nons craniocaudal diameter & $4(7 \%)$ & $764(11 \%)$ \\
\hline 3rd ventricle lateral diameter & $3(5 \%)$ & $363(5 \%)$ \\
\hline Brain total surface area & $2(3 \%)$ & $197(3 \%)$ \\
\hline $\mathrm{R}$ ainstem tentorium angle & $2(3 \%)$ & $215(3 \%)$ \\
\hline Cerebellar hemisphere anteroposterior diameter & $2(3 \%)$ & $51(1 \%)$ \\
\hline rebellar herniation level & $2(3 \%)$ & $363(5 \%)$ \\
\hline Foramen magnum anteroposterior diameter & $2(3 \%)$ & $363(5 \%)$ \\
\hline cerhemispheric distance & $2(3 \%)$ & $309(5 \%)$ \\
\hline $\mathrm{N}$ ural defect length & $2(3 \%)$ & $83(1 \%)$ \\
\hline Opercular measurements & $2(3 \%)$ & $289(4 \%)$ \\
\hline Vermis perimeter & $2(3 \%)$ & $371(5 \%)$ \\
\hline 4th ventricle angle & $1(2 \%)$ & $132(2 \%)$ \\
\hline 4th ventricle craniocaudal diameter & $1(2 \%)$ & $132(2 \%)$ \\
\hline Brainstem kinking level & $1(2 \%)$ & $326(5 \%)$ \\
\hline Brainstem surface area & $1(2 \%)$ & $220(3 \%)$ \\
\hline Cavum septum pellucidum lateral diameter & $1(2 \%)$ & $82(1 \%)$ \\
\hline Cerebellum perimeter & $1(2 \%)$ & $220(3 \%)$ \\
\hline Cerebellum surface area & $1(2 \%)$ & $220(3 \%)$ \\
\hline Cisterna magna surface area & $1(2 \%)$ & $220(3 \%)$ \\
\hline
\end{tabular}




\begin{tabular}{|c|c|c|}
\hline Cerebellar primary fissure angle & $1(2 \%)$ & $132(2 \%)$ \\
\hline Cerebellar primary fissure depth & $1(2 \%)$ & $98(1 \%)$ \\
\hline Clivovermian angle & $1(2 \%)$ & $7(<1 \%)$ \\
\hline External intraocular lateral diameter & $1(2 \%)$ & $56(1 \%)$ \\
\hline Internal intraocular lateral diameter & $1(2 \%)$ & $56(1 \%)$ \\
\hline Interpeduncular fossa anteroposterior diameter & $1(2 \%)$ & $36(1 \%)$ \\
\hline Midbrain/isthmus anteroposterior diameter & $1(2 \%)$ & $36(1 \%)$ \\
\hline Medulla anteroposterior diameter & $1(2 \%)$ & $98(1 \%)$ \\
\hline Medulla craniocaudal diameter & $1(2 \%)$ & $326(5 \%)$ \\
\hline Nesencephalic anteroposterior diameter & $1(2 \%)$ & $169(2 \%)$ \\
\hline Mamillopontine craniocaudal distance & $1(2 \%)$ & $326(5 \%)$ \\
\hline Occipital angle & $1(2 \%)$ & $367(5 \%)$ \\
\hline$D$ sterior fossa angle & $1(2 \%)$ & $54(1 \%)$ \\
\hline Posterior fossa CSF area (including vermis) & $1(2 \%)$ & $121(2 \%)$ \\
\hline Posterior fossa perimeter & $1(2 \%)$ & $121(2 \%)$ \\
\hline rons surface area & $1(2 \%)$ & $220(3 \%)$ \\
\hline Superior posterior fossa angle & $1(2 \%)$ & $121(2 \%)$ \\
\hline Tentorial angle & $1(2 \%)$ & $367(5 \%)$ \\
\hline ntoroclivus angle & $1(2 \%)$ & $7(<1 \%)$ \\
\hline Tentorium length & $1(2 \%)$ & $326(5 \%)$ \\
\hline Tentorovermian angle & $1(2 \%)$ & $7(<1 \%)$ \\
\hline Vermian crest angle & $1(2 \%)$ & $132(2 \%)$ \\
\hline vermis lateral diameter & $1(2 \%)$ & $64(1 \%)$ \\
\hline
\end{tabular}


Table 2. Measurements distinguishing a diagnosis from control.

(cisterna magna), CNS (central nervous system), CSF (cerebrospinal fluid), CSOA (clivus supra-occipital angle), HC (head circumference), IVD (inferior

vermian distance), PFA (posterior fossa abnormalities), SA (surface area), TCD (transverse cerebellar diameter), TVA (tegmento-vermian angle)

\begin{tabular}{|c|c|c|}
\hline Publications & Diagnosis vs control & Correlating measurements or calculations \\
\hline $\begin{array}{l}\text { ladini 2006, Reichel 2003, Robinson } \\
\text { 2006a, Robinson 2006b, Twickler } 2002\end{array}$ & CNS abnormalities (including PFAs) & $\begin{array}{l}\text { Cranial biparietal diameter, } \mathrm{HC} \text {, tentoro-clivus angle, vermis } \\
\text { craniocaudal diameter:biparietal diameter, clivo-vermian angle, } \\
\text { TVA, CM depth, lateral ventricle transverse diameter }\end{array}$ \\
\hline $\begin{array}{l}\text { r 2015, Goncalves 2016, Spinelli 2019, } \\
\text { T:'ea 2007, Twickler 2007, Vatansever } \\
\text { 2013, Wong } 2012\end{array}$ & PFAs & $\begin{array}{l}\text { IVD, posterior fossa SA, vermian crest angle, TVA, cerebellar } \\
\text { hemisphere SA right:left, TCD, cerebellum SA, cerebellum } \\
\text { perimeter, vermis SA (total, anterior lobe and posterior lobe), CM } \\
\text { depth, CM SA, vermis SA:CM SA, vermis SA anterior } \\
\text { lobe:posterior lobe, vermis anteroposterior diameter, vermis } \\
\text { craniocaudal diameter, vermis perimeter, cerebellar primary } \\
\text { fissure angle, pons anteroposterior diameter, 4th ventricle angle, } \\
\text { 4th ventricle craniocaudal diameter, 4th ventricle anteroposterior } \\
\text { diameter, cerebellar hemisphere lateral width }\end{array}$ \\
\hline $\begin{array}{l}\text { Abele 2013, Aertsen 2019, Danzer 2007, } \\
\text { Rf thmann 2017, Steinwendner 2011, } \\
\text { Woitek } 2014\end{array}$ & Neural tube defect & $\begin{array}{l}\text { HC, biparietal diameter (cerebral, cranial), lateral ventricle } \\
\text { transverse diameter, brain thickness calculations, TCD, vermis } \\
\text { anteroposterior diameter, posterior fossa CSF calculations, 4th } \\
\text { ventricle anteroposterior diameter, 4th ventricle lateral diameter, } \\
\text { CM depth,cerebellar herniation level, posterior fossa transverse } \\
\text { diameter, CSOA, posterior fossa SA, posterior fossa volume } \\
\text { calculation (posterior fossa surface area x posterior fossa } \\
\text { transverse diameter/2), TCD:posterior fossa transverse diameter }\end{array}$ \\
\hline saleem 2010 & Joubert syndrome & $\begin{array}{l}\text { CM depth, interpeduncular fossa anteroposterior } \\
\text { diameter:midbrain/isthmus anteroposterior diameter, } \\
\text { interpeduncular fossa anteroposterior diameter:4th ventricle } \\
\text { anteroposterior diameter, TCD, vermis craniocaudal diameter }\end{array}$ \\
\hline
\end{tabular}


Damodaram 2012, Sanz-Cortes 2014

Wong 2016
Small for gestational age

Congenital heart disease

Down Syndrome
$T C D$, vermis craniocaudal diameter, vermis anteroposterior diameter, TVA, cerebral biparietal diameter, pons

anteroposterior diameter:biparietal diameter, medulla anteroposterior diameter:biparietal diameter, vermis anteroposterior diameter:biparietal diameter, vermis craniocaudal diameter:biparietal diameter, cerebellar primary fissure depth:biparietal diameter

Opercular measurement (inside opening antero-posterior

diameter), lateral ventricle transverse diameter, vermis craniocaudal diameter

$T C D$, vermis anteroposterior diameter, vermis craniocaudal diameter, vermis SA, fronto-occipital diameter (cerebral, cranial), $\mathrm{HC}$ 
Table 3. Measurements associated with outcomes.

(cisterna magna), GA (gestational age), IVD (inferior vermian distance), MRI (magnetic resonance imaging), SGA (small for gestational age)

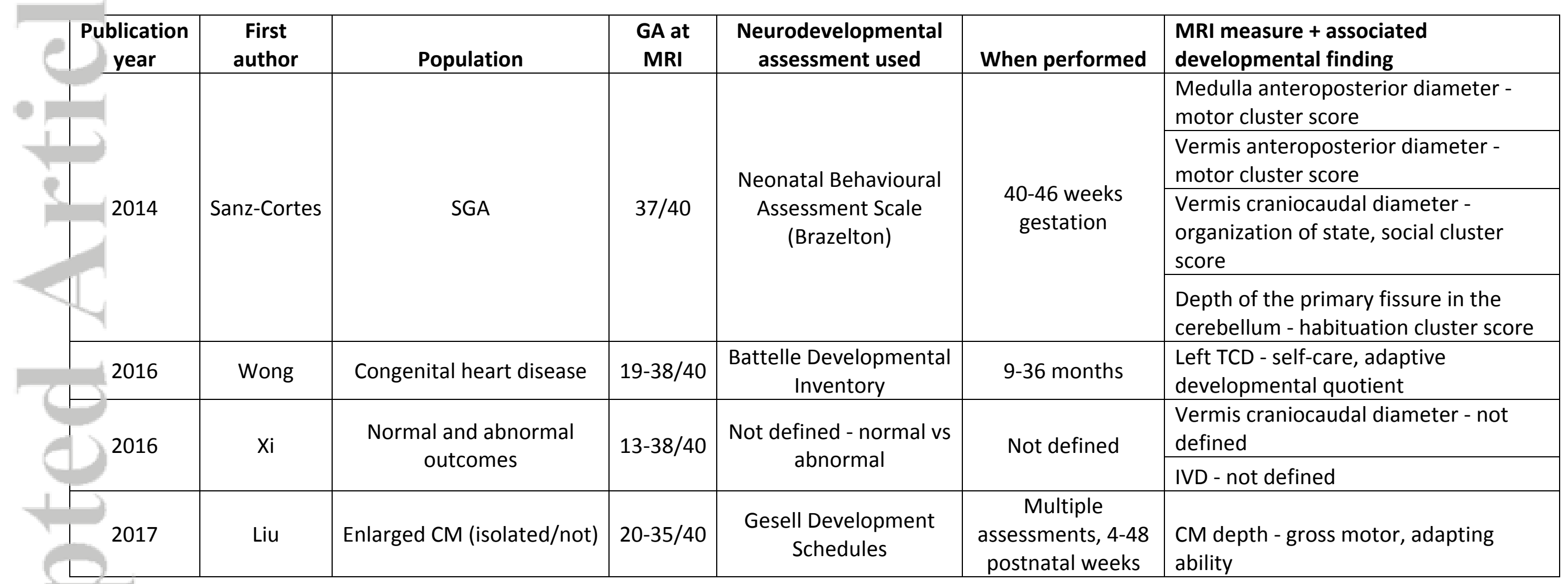


Initial search results

$$
n=24934
$$

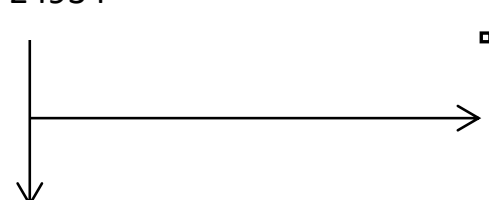

Excluded, including duplicate papers $\mathrm{n}=23132$

- Titles and abstracts

identified and screened

$$
\mathrm{n}=1802
$$

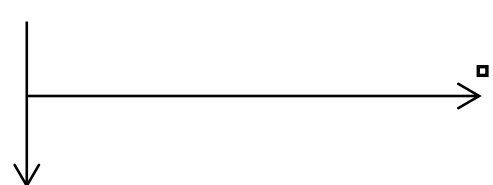

Excluded $\mathrm{n}=998$

Full copies retrieved and

assessed for eligibility

$$
\mathrm{n}=804
$$

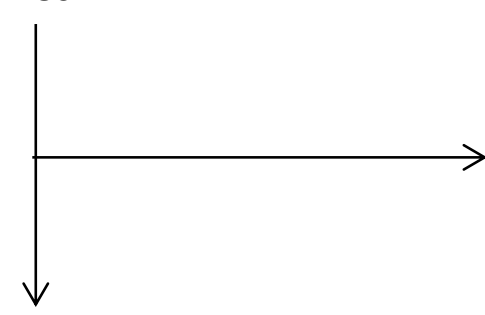

口

Reviews $\mathrm{n}=333$

Qualitative assessments and/or

insufficient numbers $n=161$

Other imaging techniques $n=240$

Duplicate data $n=11$

\section{Publications included in}

systematic review

$$
\mathrm{n}=59
$$




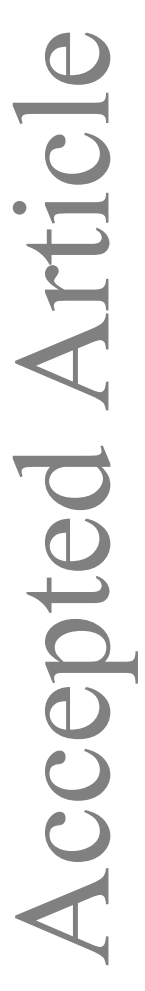




\section{aratu}

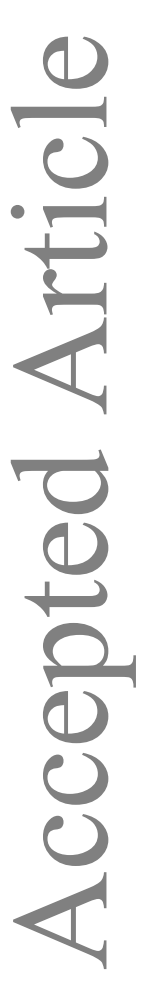




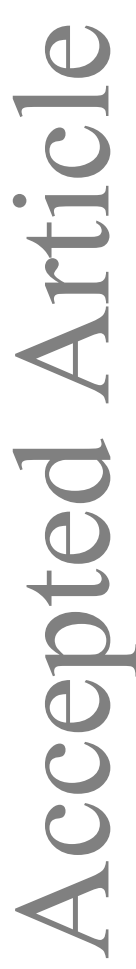

Dest 


\section{Measurements correlated with gestational age}

- $4^{\text {th }}$ ventricle angle

- $4^{\text {th }}$ ventricle craniocaudal diameter

- $4^{\text {th }}$ ventricle anteroposterior diameter

- Biparietal diameter (cerebral, cranial)

- Brainstem surface area

- Cerebellum perimeter

- Cerebellar primary fissure angle

- Cerebellum surface area

- Cisterna magna surface area

- Corpus callosum craniocaudal length

- Fronto-occipital distance (cerebral, cranial)

- Head circumference

- Intra-ocular latero-lateral diameters (internal, external)

- Pons anteroposterior diameter

- Pons craniocaudal diameter

- Pons surface area

- Posterior fossa surface area

- Posterior fossa transverse diameter

- Tentorial angle

- Trans-cerebellar diameter

- Occipital angle

- Opercular measurements

- Vermis craniocaudal diameter

- Vermis perimeter

- Vermis surface area

- Vermis latero-lateral diameter

\section{Measurements unchanged with gestational age}

- Cisterna magna depth

- Clivus supra-occipital distance

- Inferior vermian distance

(anteroposterior)

- Lateral ventricle

transverse diameter
- $3^{\text {rd }}$ ventricle lateral diameter

- Brainstem tentorium angle

- Cavum septum pellucidum lateral diameter

- Cerebellar herniation level

- Clivo-vermian angle

- Inter-hemispheric lateral distance

- Mesencephalic craniocaudal diameter

- Superior posterior fossa angle

- Tegmento-vermian angle

- Tentoro-clivus angle

- Tentoro-vermian angle 


\section{Measurements for all fetal MRI assessments of the posterior fossa:}

\section{Posterior fossa}

Cisterna magna depth

\section{Cerebellum}

Fourth ventricle lateral diameter

Inferior vermian distance

Transcerebellar diameter

Vermis anteroposterior diameter Vermis craniocaudal diameter

(anteroposterior)

Vermis surface area

\section{Brainstem}

Pons anteroposterior diameter

Pons craniocaudal diameter

Occipital angle

Tegmento-vermian angle

\section{Supratentorial/other}

Cerebral/cranial biparietal diameter

Cerebral/cranial fronto-occipital diameter

Lateral ventricle transverse diameter

\section{Joubert syndrome:}

Interpeduncular fossa anteroposterior diameter

Midbrain/isthmus anteroposterior diameter

\section{Suspected specific posterior fossa abnormality?}

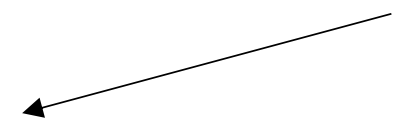

\section{Neural tube defect:}

Cerebellar herniation level Cerebellar surface area

Clivus-supraoccipital angle Foramen magnum anteroposterior diameter Fourth ventricle anteroposterior diameter

Posterior fossa surface area

Posterior fossa transverse diameter 